\title{
Randomised phase II evaluation of irinotecan plus high-dose 5-fluorouracil and leucovorin (ILF) vs 5-fluorouracil, leucovorin, and etoposide (ELF) in untreated metastatic gastric cancer
}

\section{Moehler', A Eimermacher', J Siebler', T Höhler', A Wein², M Menges ${ }^{3}$, D Flieger ${ }^{4}, \mathrm{~T}$ Junginger', T Geer ${ }^{5}$, E Gracien ${ }^{6}$, PR Galle' and M Heike ${ }^{*, 7}$}

'Klinikum der Johannes-Gutenberg-Universität, Mainz, Dortmund, Germany; ${ }^{2}$ Universtitätsklinik Erlangen, Erlangen, Dortmund, Germany;

${ }^{3}$ Universitätskliniken des Saarlandes, Homburg/Saar, Dortmund, Germany; ${ }^{4}$ Klinikum Aschaffenburg, Aschaffenburg, Dortmund, Germany; ${ }^{5}$ Diakonie Krankenhaus, Schwäbish Hall, Dortmund, Germany; ${ }^{6}$ Aventis Pharma Deutschland GmbH, Bad Soden/Ts; ${ }^{7}$ Med. Department Mitte, Klinikum Dortmund $\mathrm{gGmbH}$, Beurhausstr. 10, Dortmund 44/37, Germany

An open-label randomised comparison of efficacy and tolerability of irinotecan plus high-dose 5-fluorouracil (5-FU) and leucovorin (LV) (ILF) with etoposide plus 5-FU/LV (ELF) in patients with untreated metastatic or locally advanced gastric cancer. One cycle of ILF comprised six once-weekly infusions of irinotecan $80 \mathrm{mg} \mathrm{m}^{-2}$, LV $500 \mathrm{mg} \mathrm{m}^{-2}$, 24-h 5-FU $2000 \mathrm{mg} \mathrm{m}^{-2}$, and ELF comprised three once-daily doses of etoposide $120 \mathrm{mg} \mathrm{m}^{-2}$, LV $300 \mathrm{mg} \mathrm{m}^{-2}, 5-\mathrm{FU} 500 \mathrm{mg} \mathrm{m}^{-2}$. In all, 56 patients received ILF and 58 ELF. Median age was 62 years, Karnofsky performance $90 \%$, and disease status was comparable for both arms. The objective clinical response rates after 14 weeks treatment (primary end point) were 30\% for ILF and 17\% for ELF (risk ratio (RR) 0.57, 95\% confidence interval (Cl) $0.29-1.13, P=0.0766)$. Overall response rates over the entire treatment period for ILF and ELF were 43 and $24 \%$, respectively (RR $0.56,95 \% \mathrm{Cl} 0.33-0.97 ; P=0.0467)$. For ILF and ELF, respectively, median progression-free survival was 4.5 vs 2.3 months, time to treatment failure was 3.6 vs 2.2 months $(P=0.4542)$, and overall survival was 10.8 vs 8.3 months $(P=0.2818)$. Both regimens were well tolerated, the main grade $3 / 4$ toxicities being diarrhoea (I $8 \%$, ILF) and neutropenia (57\%, ELF). The data from this randomised phase II study indicate that ILF provides a better response rate than ELF, and that ILF should be investigated further for the treatment of metastatic gastric cancer.

British Journal of Cancer (2005) 92, 2122 -2128. doi:10.1038/sj.bjc.6602649 www.bjcancer.com

Published online 7 June 2005

(c) 2005 Cancer Research UK

Keywords: ELF; 5-fluorouracil; gastric; ILF; irinotecan; metastatic

Gastric cancer is the fourth most common cancer in Europe and the third leading cause of cancer mortality (Bray et al, 2002). Although gastric cancer has declined over the past 50 years, the incidence of tumours at the gastro-oesophageal junction has increased (Blot et al, 1991). The use of chemotherapy for the management of patients with advanced gastric cancer, who have limited treatment options (Hohenberger and Gretschel, 2003), has only become widely acceptable over the last 20 years (Glimelius et al, 1997; Murad et al, 1993; Pyrhonen et al, 1995).

5-Fluorouracil (5-FU), usually in combination with leucovorin ( $\mathrm{LV}$, also referred to as folinic acid), forms the basis of most chemotherapy regimens used for the treatment of gastric cancer. A randomised phase III trial compared combinations of 5-FU with other active drugs in advanced gastric cancer: etoposide, LV and 5FU (ELF) vs infusional 5-FU plus cisplatin (FUP) vs 5-FU, doxorubicin and methotrexate (FAMTX) (Vanhoefer et al, 2000). The overall response rates (ORRs) ranged from 9\% (ELF) to $20 \%$ (FUP) and median survival times were between 6.7 months

*Correspondence: Dr M Heike; E-mail: michael.heike@klinikumdo.de Received 20 January 2005; revised 13 April 2005; accepted 2 May 2005; published online 7 June 2005
(FAMTX) and 7.2 months (both ELF and FUP). The observed differences were not statistically significant and there is still no definitive regimen for the treatment of gastric cancer. The combination of epirubicin, cisplatin and continuous infusion 5FU (ECF) has been proposed as a standard first-line therapy for gastric cancer as a consequence of its significantly improved response rate $(46 \%)$ and survival (8.7 months) when compared with FAMTX (Waters et al, 1999). More recently, ELF has been shown to provide better disease control (complete response $(\mathrm{CR})+$ partial response $(\mathrm{PR})+$ stable disease $(\mathrm{SD})$ ) for patients with proximal rather than distal tumours (85 vs 48\%, $P=0.04$ ) (Schulze-Bergkamen et al, 2002). Tolerability, toxicity and ease of administration have become major determinants for selecting an appropriate therapy and ELF has emerged as a convenient, welltolerated regimen that can be administered on an outpatient basis (Vanhoefer et al, 2000; Schulze-Bergkamen et al, 2002).

Irinotecan (CPT-11, Camptosar; Pfizer Oncology, New York, USA) inhibits topoisomerase I thereby disrupting DNA replication and cell division within tumour cells. Response rates between 20 and $23 \%$ have been reported for irinotecan monotherapy in untreated gastric cancer (Futatsuki et al, 1994; Kohne et al, 2003). In patients who had failed previous therapy, irinotecan 
(180 $\mathrm{mg} \mathrm{m}^{-2}$ ) combined with 5 -FU (400 $\mathrm{mg} \mathrm{m}^{-2}$, bolus) and LV $\left(125 \mathrm{mg} \mathrm{m}^{-2}\right.$ ) followed by 5 -FU infusion $\left(1200 \mathrm{mg} \mathrm{m}^{-2}\right.$ over $48 \mathrm{~h}$ ) yielded a response rate of $29 \%$, while a further $34 \%$ of patients achieved SD (Assersohn et al, 2004). Irinotecan with bolus-LV/5FU in the first-line treatment of gastric cancer provided a response rate of $22 \%$ (Blanke et al, 2001). However, this regimen (irinotecan $125 \mathrm{mg} \mathrm{m}^{-2}$, LV $20 \mathrm{mg} \mathrm{m}^{-2}$ plus 5-FU $500 \mathrm{mg} \mathrm{m}^{-2}$, all given weekly for 4 weeks followed by a 2-week rest) was associated with a high incidence of severe diarrhoea $(28 \%)$ and neutropenia $(36 \%)$ infection leading to substantial dose modifications (Blanke et al, 2001). By comparison, the combination of irinotecan with continuous rather than bolus infusions of LV/5-FU exhibited a lower incidence of grade 3 and 4 toxicities in colorectal cancer patients (Douillard et al, 2000; Saltz et al, 2000; Bouzid et al, 2003). Therefore, we have investigated a weekly dose of irinotecan $\left(80 \mathrm{mg} \mathrm{m}^{-2}\right)$ in combination with $\mathrm{LV}\left(500 \mathrm{mg} \mathrm{m}^{-2}\right)$ and continuous 5 -FU (2000 $\mathrm{mg} \mathrm{m}^{-2}$ over $24 \mathrm{~h}$ ) according to the AIO (Arbeitsgemeinschaft Internistische Onkologie) regimen (i.e. ILF) in gastric cancer patients. In a previous phase I study of ILF in the first- and second-line treatment of gastric cancer, we observed a response rate of $20 \%$ with a further $36 \%$ of patients reporting SD (Moehler et al, 2003). Importantly, toxicity was sufficiently manageable to allow outpatient-based treatment. Therefore, we initiated the present randomised, controlled, phase II study to compare the efficacy and safety of ILF with ELF in the first-line treatment of metastatic gastric cancer.

\section{PATIENTS AND METHODS}

\section{Patients}

Eligible patients had untreated histologically proven gastric adenocarcinoma, or adenocarcinoma of the oesophagogastric junction with measurable metastatic disease and/or locally recurrent nodal involvement, were aged between 18 and 75 years with a Karnofsky performance score (KPS) $\geqslant 60$ and a life expectancy $>12$ weeks. Patients were required to have adequate haematological (neutrophils $\geqslant 2.0 \times 10^{9} 1^{-1}$, platelets $\geqslant 150 \times 10^{9} 1^{-1}$; haemoglobin $\geqslant 10 \mathrm{~g} \mathrm{dl}^{-1}$ ), hepatic (total bilirubin $\leqslant 1.25 \times$ upper normal limit (UNL); aspartate (AST) and alanine (ALT) aminotransferases $\leqslant 3 \times \mathrm{UNL}$ ) and renal function (creatinine $<1.25 \times \mathrm{UNL}$ ). Patients with previous cancer therapies were excluded from the study.

All patients provided signed and dated consent before entering the trial. The study was conducted in accordance with the principles of the Declaration of Helsinki and Good Clinical Practice guidelines and the protocol was initially approved by the Ethics committee of Aerztekammer Rheinland-Pfalz and later by all Ethics committees responsible for participating centres.

\section{Study design and randomisation}

This was an open-label, multicentre, phase II randomised trial with two treatment arms. Patients were randomly assigned and stratified according to centre, peritoneal involvement (yes/no) and prior gastrectomy (yes/no). The randomisation process was centralised and performed by the Coordination Centre for Clinical Trials (KKS), Mainz, Germany.

\section{Administration of study drugs and dose adjustment}

Patients assigned to ILF (Arm A) received irinotecan $80 \mathrm{mg} \mathrm{m}^{-2}$ intravenously (i.v.) over $60-90 \mathrm{~min}$ followed by LV $500 \mathrm{mg} \mathrm{m}^{-2}$ i.v. over $60 \mathrm{~min}$ and then 5 -FU $2000 \mathrm{mg} \mathrm{m}^{-2}$ i.v. over $24 \mathrm{~h}$, on day 1 . Each cycle comprised six once-weekly treatments followed by a 13day rest period. Systemic prophylactic atropine $(0.25 \mathrm{mg})$ injections for irinotecan-related acute cholinergic symptoms were allowed for the first cycle but not recommended. Prophylactic treatment for delayed diarrhoea was not permitted. However, patients were carefully informed of the potential risk of delayed diarrhoea and neutropenia and the need for early intervention with loperamide, metoclopramide, antibiotics, or hospitalisation and parenteral rehydration in case of refractory diarrhoea $(>48 \mathrm{~h})$. Antiemetic treatment was performed using metoclopramide or HT-3 antagonists in a sequential manner. The prophylactic use of colony-stimulating factors was not permitted.

Patients assigned to ELF (Arm B) received etoposide $120 \mathrm{mg} \mathrm{m}^{-2}$ i.v. over $60 \mathrm{~min}$, LV $300 \mathrm{mg} \mathrm{m}^{-2}$ i.v. over 5-10 min and then 5-FU $500 \mathrm{mg} \mathrm{m}^{-2}$ bolus i.v. over $2-4 \mathrm{~min}$, on day 1 . Each cycle comprised three applications on consecutive days $(1-3)$ followed by an 18-day rest.

All study treatments were administered until disease progression, unacceptable toxicity or withdrawal of consent. In the event of toxicity (defined by the National Cancer Institute of Canada expanded common toxicity criteria; NCIC-CTC), treatment delays or dose reductions could be applied as follows. If at any time during a cycle there were moderate reductions in haematological function (neutrophil count $0.5-1.5 \times 10^{9} \mathrm{l}^{-1}$, platelet count $25-$ $75 \times 10^{9} 1^{-1}$ ) or moderate diarrhoea or stomatitis ( $>$ grade 1 ), the next administration could be delayed for up to 2 weeks. If at any time haematological abnormalities were noted (neutrophils $<0.5 \times 10^{9} 1^{-1}$, neutrophils $<1 \times 10^{9} 1^{-1}$ with infection or fever, platelets $<25 \times 10^{9} 1^{-1}$ ) or if there were $\geqslant$ grade 3 or 4 diarrhoea or stomatitis, treatment had to be delayed until recovery to moderate levels (as described above) after which the following dose reductions were applied. For Arm A, 5-FU was reduced to $1600 \mathrm{mg} \mathrm{m}^{-2}$ and irinotecan to $65 \mathrm{mg} \mathrm{m}^{-2}$. For Arm B, in the case of haematological toxicity, etoposide had to be reduced to $100 \mathrm{mg} \mathrm{m}^{-2}$ and 5-FU to $400 \mathrm{mg} \mathrm{m}^{-2}$, and in the case of diarrhoea or stomatitis, $5-\mathrm{FU}$ was reduced to $400 \mathrm{mg} \mathrm{m}^{-2}$. If a condition persisted despite dose reduction, or if a patient experienced myocardial infarction, treatment was terminated. In the case of hand-foot syndrome, the dose of 5-FU was to be reduced by $20 \%$. Delayed diarrhoea was treated immediately with loperamide and rehydration and, if associated with severe neutropenia, a broadspectrum antibiotic. Hospitalisation with i.v. rehydration was required for grade 4 or persistent $(>48 \mathrm{~h}$ ) diarrhoea, concomitant vomiting, fever, or KPS $<60 \%$.

\section{Study evaluations}

At baseline up to five measurable lesions per organ and 10 lesions in total were to be identified as target lesions, measured using computed tomography (CT), and recorded according to the RECIST system (Response Evaluation Criteria In Solid Tumours; Therasse et al, 2000). The sum of the longest diameters for all target lesions was used as a reference for determining objective tumour response. Tumour responses were evaluated at week 7, week 14 and then every two cycles for patients receiving ILF or every four cycles for patients receiving ELF. Responses were determined according to RECIST as follows: complete response was defined as the disappearance of all target and nontarget lesions with no new lesions and confirmed by two observations at least 4 weeks apart; PR was defined as a reduction of $30 \%$ or more in the sums of the longest diameters of all measurable lesions relative to baseline with no new lesions; no change (NC) was defined as neither sufficient shrinkage to qualify for PR nor sufficient increase to qualify for progressive disease (PD) with no new lesions; and PD was defined as $\geqslant 20 \%$ increase in the sum of the longest diameters, the occurrence of nontarget lesions (e.g. pleural effusion or ascites) or the appearance of brain metastases independently of performance at sites outside the brain.

Safety and tolerability were assessed by regular clinical examinations and assessments of adverse events (weekly, at the end of treatment and at every 3 months of follow-up), disease symptoms, KPS, haematological and biochemical parameters. 


\section{Statistical analysis}

The primary end point was objective clinical response $(C R+P R)$ based on an interim analysis following 14 weeks of treatment. The one-sided exact Fisher's test was used to compare the treatment arms at the significance level $\alpha=5 \%$. The analyses were performed on an intention-to-treat basis including all patients who were treated in the study.

The secondary end points were ORR (for the entire treatment period), time to progression, tumour growth control, time to treatment failure (including progression, death or withdrawal) and survival.

Time to event data were described by Kaplan-Meier estimates and treatment groups were compared by log-rank test. Time to event data were further evaluated by appropriate proportional Cox's models and results were summarised by hazard ratio point and $95 \%$ confidence interval (CI) estimates, and $P$-values of Wald $\chi^{2}$ test. Binary data were described by risk ratio (RR) point and 95\% CI estimates and treatment groups were compared by exact Fisher's test. Binary data were further evaluated by appropriate logistic regression models and were summarised by odds ratio point and $95 \% \mathrm{CI}$ estimates and $P$-values of Wald $\chi^{2}$ test. If not specified otherwise, $P$-values are presented from two-sided tests and two-sided $95 \%$ CI are presented. All analyses were performed using SAS version 6.12.

\section{RESULTS}

\section{Patient characteristics}

In all, 120 patients from 17 centres in Germany were randomised into the study between November 2000 and April 2003. Two patients from Arm A and four from Arm B withdrew without receiving study treatment; therefore, the intention-to-treat population contained 114 patients (56 received ILF and 58 received ELF). The baseline characteristics were well balanced between the two treatment groups (Table 1). The median age of patients was 62 years and the median KPS was $90 \%$. In around one-third $(31 \%)$ of patients, the primary tumour site was the oesophagogastric junction, $62 \%$ of patients had liver metastases and in $77 \%$ two or more organs were involved.

\section{Response rates}

The objective clinical response rates following 14 weeks of treatment (primary end point) were $30 \%$ for ILF compared with $17 \%$ for ELF (RR 0.57, 95\% CI $0.29-1.13, P=0.0766$ ). The ORRs for the entire treatment period and including all assessments prior to discontinuation were $43 \%$ ( 24 of the 56 ) for ILF and $24 \%$ (14 of the 58) for ELF (Table 2). The increased response rate provided by ILF compared with ELF was statistically significant $(R R=0.56$; 95\% $\mathrm{CI}=0.33-0.97 ; \quad P=0.0467$.) The tumour control rates $(\mathrm{CR}+\mathrm{PR}+\mathrm{NC})$ were $63 \%$ (35 of the 56$)$ and $41 \%$ (24 of the 58 ), respectively.

Logistic regression analysis indicated that a baseline KPS $\leqslant 80 \%$ reduced the likelihood of a response by 59\% compared with patients whose KPS was greater than $80 \%(P=0.038)$ (Table 3$)$. After adjustment for KPS, peritoneal involvement and surgery for primary tumour, the regression model also demonstrated that ILF was $138 \%$ more likely to provide a response when compared with the ELF regimen (Table 3, $P=0.042$ ).

\section{Progression-free survival, treatment failure and overall survival}

At the last data cutoff, the median follow-up was 9.4 months in Arm A and 5.8 months in Arm B. At this time, 96 of the 114 patients had died. Disease progression was the major cause of
Table I Patient and disease characteristics at baseline (intention-to-treat population)

\begin{tabular}{|c|c|c|}
\hline & $\begin{array}{c}\text { Irinotecan+5- } \\
\text { FU/LV }\end{array}$ & $\begin{array}{c}\text { Etoposide }+5 \\
\text { FU/LV }\end{array}$ \\
\hline No. of exposed patients & 56 & 58 \\
\hline \multicolumn{3}{|l|}{ Gender (n (\%)) } \\
\hline Male & $40(7 \mid)$ & $49(85)$ \\
\hline Female & $16(29)$ & $9(16)$ \\
\hline \multicolumn{3}{|l|}{ Age (years) } \\
\hline Median (range) & $61(4 \mid-73)$ & $63(34-76)$ \\
\hline \multicolumn{3}{|l|}{ KPS } \\
\hline Median value & 90 & 85 \\
\hline \multicolumn{3}{|l|}{ Distribution (n (\%)) } \\
\hline $60+70$ & $3(5)$ & $7(12)$ \\
\hline 80 & $21(38)$ & $22(38)$ \\
\hline 90 & $28(50)$ & $21(36)$ \\
\hline 100 & $4(7)$ & $8(14)$ \\
\hline \multicolumn{3}{|l|}{ Primary tumour location (n (\%)) } \\
\hline Stomach & $37(66)$ & $42(72)$ \\
\hline Oesophagogastric junction & $19(34)$ & $16(28)$ \\
\hline \multicolumn{3}{|l|}{ Median time (months (range)) since } \\
\hline Histological confirmation & $1.5(0-18 \mid)$ & $1.4(0-65)$ \\
\hline Diagnosis of metastasis & $0.7(0-12)$ & $0.5(0-13)$ \\
\hline \multicolumn{3}{|l|}{ Prior surgery } \\
\hline Number with surgery (\%) & $29(52)$ & $31(53)$ \\
\hline Median months since surgery (range) & $7.7(0-181)$ & II.I (0-65) \\
\hline \multicolumn{3}{|l|}{ Location of metastases at entry (n (\%)) } \\
\hline Skin & 0 & I (2) \\
\hline Liver & $34(61)$ & $37(64)$ \\
\hline Lung & $12(21)$ & $5(9)$ \\
\hline Lymph nodes & $40(7 \mid)$ & $47(81)$ \\
\hline Bone marrow & 0 & 0 \\
\hline Bone & $4(7)$ & I (2) \\
\hline Peritoneum & $10(18)$ & II (19) \\
\hline Other & $20(36)$ & $23(40)$ \\
\hline \multicolumn{3}{|l|}{ Number of involved organs (n (\%)) } \\
\hline । & $13(23)$ & $13(22)$ \\
\hline 2 & $25(45)$ & $25(43)$ \\
\hline 3 & $15(27)$ & $18(31)$ \\
\hline 4 & $3(5)$ & $2(3)$ \\
\hline
\end{tabular}

KPS = Karnofsky performance score.

death and accounted for $79 \%$ of patients in both treatment groups. One patient from the ILF arm did not comply with the provided recommendations for the treatment of prolonged grade 3 diarrhoea and consequently died (i.e. toxic death). One patient in the ELF arm died from a cardiovascular event.

Compared with ELF, the ILF regimen extended median progression-free survival, median time to treatment failure and median overall survival (Table 4). However, when the treatment groups were compared by log-rank test, there was no significant difference between the two treatments for any of these parameters (e.g. the Kaplan-Meier survival plot as shown in Figure 1).

Investigational analyses found that the risk of progression was increased in patients with a primary tumour in the oesophagogastric junction and in those with metastatic involvement in two or more organs (Table 3). As would be expected, the risk of death was increased in patients with a low KPS, in those with two or more involved organs and in those with peritoneal involvement who received ELF (Table 3). 
ILF vs ELF for the treatment of metastatic gastric cancer

M Moehler et al

Table 2 Response to therapy in the entire treatment period

\begin{tabular}{lcc}
\hline & \multicolumn{2}{c}{ Number (\%) of patients } \\
\cline { 2 - 3 } Response category & $\begin{array}{c}\text { Irinotecan+5-FU/LV } \\
(\mathbf{N}=\mathbf{5 6})\end{array}$ & $\begin{array}{c}\text { Etoposide+5-FU/LV } \\
\mathbf{( N = 5 8 )}\end{array}$ \\
\hline CR & $2(4)$ & 0 \\
PR & $22(39)$ & $14(24)$ \\
NC & $11(20)$ & $10(17)$ \\
PD & $13(23)$ & $27(47)$ \\
Missing & $8(14)$ & $7(12)$ \\
Overall response (CR+PR) & $24(43)$ & \\
& RR (95\% Cl), P-value & \\
& $0.56(0.33-0.97)$, & $24(4 \mid)$ \\
& $P=0.0467$ & \\
\hline Disease control & $35(63)$ & \\
(CR+PR+NC) & &
\end{tabular}

5-FU =5-fluorouracil; $L V=$ leucovorin; $C R=$ Complete response; $P R=$ partial response; $\mathrm{NC}=$ no change; $\mathrm{PD}=$ progressive disease; $\mathrm{RR}=$ risk ratio; $\mathrm{Cl}=$ confidence interval.

\section{Safety}

The median number of cycles administered in the study was two for ILF (Arm A) and three for ELF (Arm B) (Table 5). Although the median treatment duration period was over twice as long with ILF than with ELF, there were more dose administration delays (70\%) and dose reductions (75\%) with ILF than with ELF (52 and 45\%, respectively). The main reason for discontinuing study treatment was disease progression; $54 \%$ of patients receiving ILF and $72 \%$ receiving ELF. Although only one patient in each treatment group withdrew because of treatment-related toxicity, five patients receiving ILF and three patients receiving ELF either withdrew consent or refused further treatment.

The incidence of grade 3/4 haematological toxicities was low in both treatment groups with the exception of neutropenia, which was reported by $57 \%$ of patients receiving ELF (Table 6). There were more grade $3 / 4$ gastrointestinal toxic events with ILF, notably diarrhoea, which was reported by $18 \%$ of patients compared with no reports with ELF. Grade 3/4 alopecia was reported by a significant proportion of patients receiving ELF (28\%), but was only seen in $5 \%$ of those receiving ILF.

\section{DISCUSSION}

Although chemotherapy regimens offer at best a slight, albeit statistically significant, improvement in survival for patients with gastric cancer, they are associated with a degree of toxicity that limits their value as a palliative treatment (Vanhoefer et al, 2000; Schoffski, 2002; Diaz-Rubio, 2004).

The primary end point of clinical response at 14 weeks was selected so that a statistical comparison at a fixed time point could be made. However, as it is the convention in such studies, patients were treated until progression, and could respond to treatment at a later point. Therefore, the overall response and survival rates obtained from the entire dosing period provide a more clinically significant assessment of the efficacy of these regimens for discussion in relation to other trials in gastric cancer. The irinotecan-based combination provided again a greater ORR than that seen with the commonly used ELF regimen (43 vs 24\%, respectively, $P=0.0467$ ).

Overall response rates for ELF reported in previous studies range from 9 to 23\% (Vanhoefer et al, 2000; Schulze-Bergkamen
Table 3 Exploratory analysis of effects of prognostic factors on clinical outcome

\begin{tabular}{|c|c|c|}
\hline End point & Factor & $\operatorname{RR}(95 \% \mathrm{Cl})$ \\
\hline Response & $\begin{array}{l}\text { Peritoneal involvement: } \\
\text { Yes vs no } \\
\text { Surgery of primary tumour: } \\
\text { Yes vs no } \\
\text { Baseline Karnofsky status: } \\
\leqslant 80 \text { vs }>80 \\
\text { Treatment effect: } \\
\text { ELF vs ILF }\end{array}$ & $\begin{array}{c}0.43 \\
(0.13-1.47) \\
1.78 \\
(0.76-4.15) \\
0.41 * \\
(0.17-0.95) \\
0.42 * \\
(0.18-0.97)\end{array}$ \\
\hline Progression & $\begin{array}{l}\text { Peritoneal involvement: } \\
\text { Yes vs no } \\
\text { Surgery of primary tumour: } \\
\text { Yes vs no } \\
\text { ELF vs ILF } \\
\text { (in patients with Karnofsky status } \\
\leqslant 80 \text { ) } \\
\text { ELF vs ILF } \\
\text { (in patients with Karnofsky status } \\
>80 \text { ) } \\
\text { Number of organs: } \\
>\text { I vs I } \\
\text { Site of primary tumour: } \\
\text { oesophagogastric vs stomach }\end{array}$ & $\begin{array}{c}1.15 \\
(0.67-1.96) \\
0.86 \\
(0.58-1.29) \\
1.7 \\
(0.96-3.0) \\
0.8 \\
(0.47-1.39) \\
1.99 * * \\
(1.21-3.28) \\
1.91 * * \\
(1.2-3.04)\end{array}$ \\
\hline Death & $\begin{array}{l}\text { Peritoneal involvement: } \\
\text { Yes vs no } \\
\text { Surgery of primary tumour: } \\
\text { Yes vs no } \\
\text { ELF vs ILF } \\
\text { (in patients with peritoneal } \\
\text { involvement) } \\
\text { ELF vs ILF } \\
\text { (in patients without peritoneal } \\
\text { involvement) } \\
\text { Number of organs: } \\
>\text { I vs I } \\
\text { Baseline Karnofsky status: } \\
\leqslant 80 \text { vs }>80\end{array}$ & $\begin{array}{c}0.85 \\
(0.42-1.75) \\
0.69 \\
(0.46-1.06) \\
2.41 \\
(0.99-5.82) \\
1.01 \\
(0.64-1.59) \\
\\
2.56 * * \\
(1.48-4.42) \\
1.84 * * \\
(1.21-2.8)\end{array}$ \\
\hline
\end{tabular}

$\mathrm{RR}=$ risk ratio; $\mathrm{Cl}=$ confidence interval. A risk value $>1$ shows an increased likelihood of the clinical outcome in favour of the first of the two compared terms. ELF, etoposide+LV (leucovorin)+5-FU(5-fluorouracil); ILF, irinotecan+LV+5-FU; E], oesophagogastric junction. ${ }^{*} P<0.05$. $* * 0.01$ by $W$ ald $\chi^{2}$ test.

Table 4 Survival

\begin{tabular}{|c|c|c|c|}
\hline \multirow[b]{2}{*}{$\begin{array}{l}\text { Survival } \\
\text { parameter }\end{array}$} & $\begin{array}{l}\text { Irinotecan+5- } \\
\text { FU/LV }(N=56)\end{array}$ & $\begin{array}{c}\text { Etoposide+5- } \\
\text { FU/LV }(N=58)\end{array}$ & \multirow[b]{2}{*}{$\begin{array}{c}\text { Statistical } \\
\text { comparison }^{\mathrm{a}} \\
\text { Hazard ratio } \\
(95 \% \mathrm{CI})\end{array}$} \\
\hline & \multicolumn{2}{|c|}{ Median time in months $(95 \% \mathrm{CI})$} & \\
\hline $\begin{array}{l}\text { Progression-free } \\
\text { survival }\end{array}$ & $4.5(3.4-5.8)$ & $2.3(2.0-4.7)$ & $\begin{array}{l}1.10(0.75-1.62) \\
P=0.6116\end{array}$ \\
\hline $\begin{array}{l}\text { Time to treatment } \\
\text { failure }\end{array}$ & $3.6(2.4-5.1)$ & $2.2(1.5-2.9)$ & $\begin{array}{l}1.15(0.79-1.67) \\
P=0.4542\end{array}$ \\
\hline Overall survival & $10.8(9.0-13.2)$ & $8.3(6.6-11.4)$ & $\begin{array}{l}1.25(0.83-1.86) \\
P=0.28 \mid 8\end{array}$ \\
\hline
\end{tabular}

5-FU = 5-fluorouracil; $\mathrm{LV}=$ leucovorin; $\mathrm{Cl}=$ confidence interval. ${ }^{\text {a Hazard ratio }>1}$ favors irinotecan+5-FU/LV; $P$-value from log-rank test.

et al, 2002) and this compares well with the $24 \%$ response rate reported in this study. Accordingly, an ORR of nearly $50 \%$ for ILF, as seen in this study, is a substantial improvement and is in the 


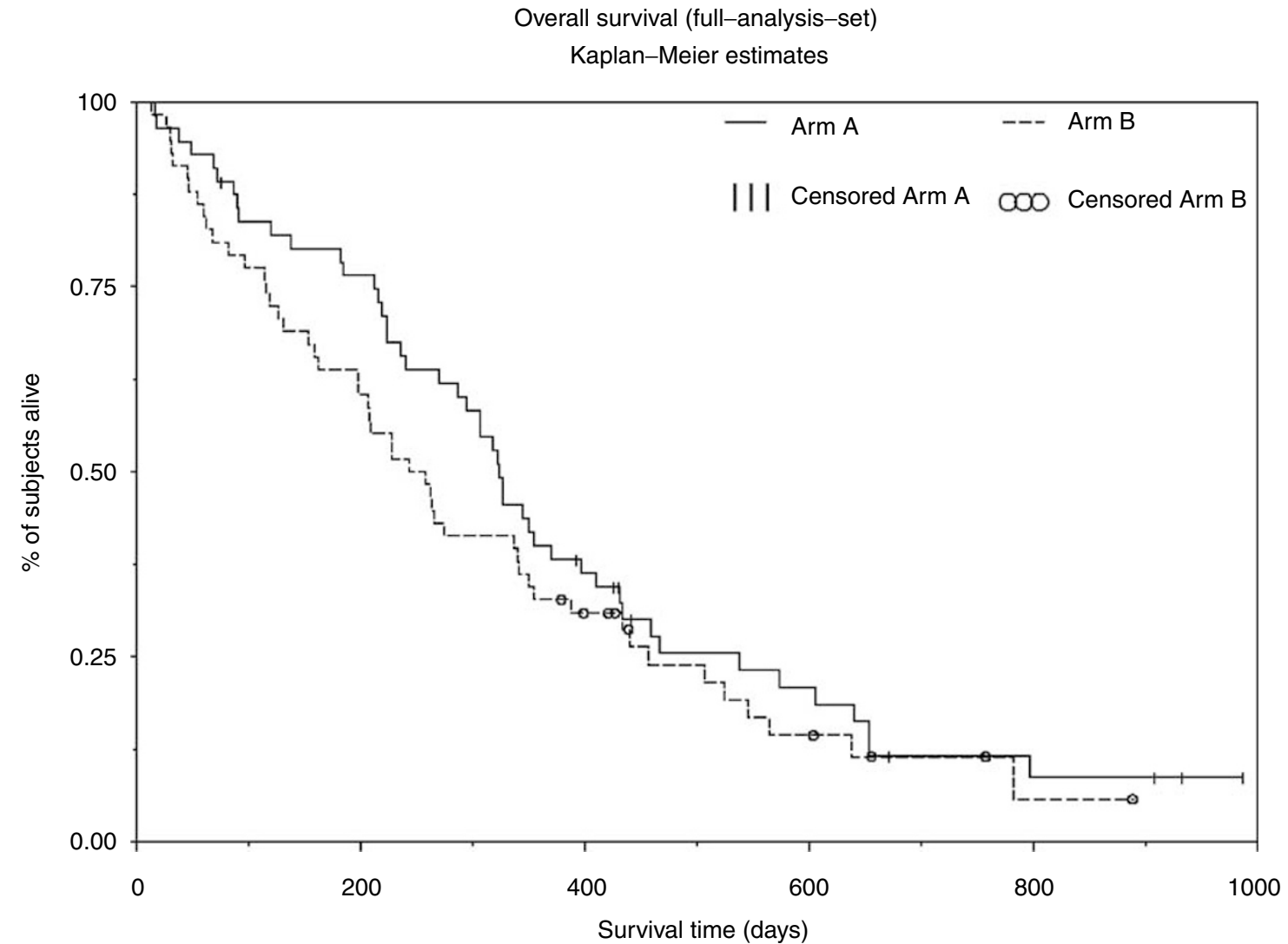

Figure I Overall survival. Arm $A=$ irinotecan + 5-fluorouracil/leucovorin (ILF), $N=56$. Arm $B=$ etoposide +5 -fluorouracil/leucovorin (ELF), $N=58$.

Table 5 Dosing information

\begin{tabular}{lcc}
\hline & $\begin{array}{c}\text { Irinotecan+5- } \\
\text { FU/LV (N=56) }\end{array}$ & $\begin{array}{c}\text { Etoposide+5- } \\
\text { FU/LV (N=58) }\end{array}$ \\
\hline $\begin{array}{l}\text { Median number of } \\
\text { cycles (range) } \\
\begin{array}{l}\text { Number of cycles } \\
\text { administered as } \\
\text { planned }\end{array}\end{array}$ & $2(0-14)$ & $3(1-19)$ \\
$\begin{array}{l}\text { Median months of } \\
\text { treatment duration } \\
\text { (range) }\end{array}$ & $33(59 \%)$ & $18(82 \%)$ \\
$\begin{array}{l}\text { Number (\%) of } \\
\text { administration } \\
\text { delays }\end{array}$ & $3.6(0-22)$ & $1.5(0-15)$ \\
$\begin{array}{l}\text { Number (\%) of } \\
\text { dose reductions }\end{array}$ & $42(75)$ & $30(52)$ \\
\hline
\end{tabular}

5-FU = 5-fluorouracil; LV = leucovorin.

range of previous reports of the use of this drug combination in this setting (Blanke et al, 2001; Moehler et al, 2003).

The overall survival data in the present study also compare well with those from previous studies. The median overall survival with ELF has been reported at 7.2 and 8.0 months (Vanhoefer et al, 2000; Schulze-Bergkamen et al, 2002), which is similar to both the 8.3 months reported here and the data reported for irinotecanbased regimens in the second-line setting between 7.0 and 7.6 months (Moehler et al, 2003; Assersohn et al, 2004). By comparison, there was a nonsignificant trend for increased median survival with ILF in this study (10.8 months) and this compares
Table 6 Grade 3 or 4 toxicity according to NCIC-CTC

\begin{tabular}{|c|c|c|}
\hline \multirow[b]{2}{*}{ Adverse event category } & $\begin{array}{l}\text { Irinotecan+5- } \\
\text { FU/LV }(N=56)\end{array}$ & $\begin{array}{l}\text { Etoposide+5- } \\
\text { FU/LV }(N=58)\end{array}$ \\
\hline & \multicolumn{2}{|c|}{$\begin{array}{l}\text { Percentage of patients in each } \\
\text { category }\end{array}$} \\
\hline \multicolumn{3}{|l|}{ Haematological toxicity } \\
\hline Anaemia & 7 & 9 \\
\hline Neutropenia & 9 & 57 \\
\hline Thrombocytopenia & 4 & 5 \\
\hline Infection with neutropenia & 4 & 3 \\
\hline Fever+neutropenia, no infection & 2 & 3 \\
\hline \multicolumn{3}{|l|}{ Gastrointestinal toxicity } \\
\hline Nausea & 16 & 7 \\
\hline Diarrhoea & 18 & 0 \\
\hline Vomiting & 7 & 5 \\
\hline \multicolumn{3}{|l|}{ Other toxicity } \\
\hline Infection without neutropenia & 2 & 7 \\
\hline Anorexia & 2 & 7 \\
\hline Alopecia & 5 & 28 \\
\hline Constipation & 2 & 0 \\
\hline
\end{tabular}

$\mathrm{NClC}-\mathrm{CTC}=$ National Cancer Institute of Canada expanded common toxicity criteria; 5 -FU = 5-fluorouracil; $\mathrm{LV}=$ leucovorin

well with data reported for more recent exploratory combinations such as capecitabine and docetaxel (10.5 months), and epirubicin, docetaxel and cisplatin (11.0 months) (Lee et al, 2004; Park et al, 2004). The same can be said of the progression-free survival period in the ILF group of 4.5 months, which compared well with the 4.1 
and 5.2 months reported recently for docetaxel-based regimens (Lee et al, 2004; Park et al, 2004). In other randomised phase II studies, continuous 5-FU/LV infusion plus irinotecan has also provided promising efficacy (ORRs of $40-42 \%$, median progression-free survival periods of 6.5-6.9 months and median overall survival periods of 10.7-11.3 months; Bouche et al, 2004; Pozzo et al, 2004). Consequently, large phase III studies are being considered to investigate irinotecan in combination with continuous 5-FU/LV infusion regimens.

When patient histories, disease status and other factors were examined for their effects on clinical outcome, those patients who were in better general health (good performance status, low tumour burden) were more likely to achieve a response and less likely to have a progression event or die, regardless of the treatment arm to which they were randomised. Patients with peritoneal involvement at presentation have a generally poorer prognosis and as a group face a desperate need for improved treatment options (Rau et al, 1996). The data from this study demonstrated that these patients are less likely to suffer a fatal event if treated with ILF rather than ELF. This is potentially an important observation for the management of these difficult to treat patients (Blot et al, 1991; Bray et al, 2002).

The extension of meaningful survival remains a major objective for oncologists who must therefore consider the impact of treatment-related toxicity. Overall, the occurrence of the toxicities in this study was consistent with the safety profiles of irinotecan, etoposide and 5-FU/LV. The ILF combination was well tolerated with a low and acceptable incidence of haematological toxicity. Gastrointestinal toxicity is a recognised side effect of ILF therapy (Douillard et al, 2000; Saltz et al, 2000), which can require hospitalisation and urgent medical intervention (Rothenberg et al, 2001). The incidence of grade 3 or 4 diarrhoea in the current study was comparable to the previous data in gastric cancer (Blanke et al, 2001; Moehler et al, 2003; Pozzo et al, 2004). With close monitoring of the patient, suitable medication and rehydration, most cases of diarrhoea can be managed effectively and do not present a significant obstacle to the clinical use of ILF.

The toxicity observed in our study was lower than that reported by Douillard et al in the pivotal European first-line trial where patients with colorectal cancer received weekly irinotecan $\left(80 \mathrm{mg} \mathrm{m}^{-2}\right)$ plus an AIO-based regimen of 24 -h high-dose 5 -FU $\left(2300 \mathrm{mg} \mathrm{m}^{-2}\right)$ preceded by $2-\mathrm{h} \mathrm{LV} 500 \mathrm{mg} \mathrm{m}^{-2}$, and grade $3 / 4$ diarrhoea was reported by $44 \%$ of patients (Douillard et al, 2000). The lower toxicity in our study might be due to the lower daily doses of 5 -FU ( $2000 \mathrm{mg} \mathrm{m}^{-2}$ administered over $24 \mathrm{~h}$ ). Work is ongoing to identify those patients who carry a specific genetic polymorphism in one of the main enzymes (UGT1A1) involved in the detoxification of irinotecan and are therefore more susceptible to the side effects of irinotecan (Mathijssen et al, 2001). Such work will improve the targeting of this useful therapy and may allow appropriate prescriptive dosing schedules on an individual basis.

The present study concurs with similar phase II studies in that the combination of irinotecan with continuous LV/5-FU (ILF) represents a potentially valuable new treatment option for metastatic gastric cancer and requires further evaluation (Bouche et al, 2004; Pozzo et al, 2004).

\section{ACKNOWLEDGEMENTS}

This work was supported by a grant from Aventis Pharma GmbH. The data from this study were presented previously at the American Society for Clinical Oncology annual meeting, 2004, Abstract No: 4064. We thank Dr A Kranich, GSO Hamburg, for supporting efficient monitoring, and Aventis Pharma Deutschland for supporting grants. We also thank all participating colleagues and centres: Markus Moehler ${ }^{1}$, Thomas Höhler ${ }^{1}$, Wolfgang Dippold $^{2}$, Heinz-Albert Dürk ${ }^{3}$, Wolfgang Fischbach ${ }^{4}$, Thomas Geer $^{5}$, Frank Gieseler ${ }^{6}$, Eckhart-Georg Hahn ${ }^{7}$, Michael Heike ${ }^{8}$, Hans-Jochen Illiger ${ }^{9}$, Joachim Mössner ${ }^{10}$, Rainer Porschen ${ }^{11}$, Jürgen Riemann ${ }^{12}$, Tilman Sauerbruch ${ }^{13}$, Wolff Schmiegel ${ }^{14}$, Wolfgang Stremmel ${ }^{15}$, Ziad Zeidan ${ }^{16}$, Stefan Zeuzem ${ }^{17}$

${ }^{1}$ Klinikum der Johannes-Gutenberg-Universität, I Medizinische Klinik und Poliklinik, Mainz, Germany; ${ }^{2}$ Katholisches Klinikum Mainz, St Vincenz- und Elisabeth-Hospital, Mainz, Germany; ${ }^{3}$ Sankt Marien Hospital, Medizinische Klinik, Hamm, Germany; ${ }^{4}$ Klinikum Aschaffenburg, Medizinische Klinik, Germany; ${ }^{5}$ Diakonie Krankenhaus, Schwäbisch Hall, Germany; ${ }^{6}$ Universitätsklinikum Kiel, I Medizinische Klinik und Poliklinik, Germany; ${ }^{7}$ Universitätsklinik Erlangen, NOZ Medizinische Klinik I, Erlangen, Germany; ${ }^{8}$ Klinikum Dortmund $\mathrm{gGmbH}$, Medizinische Klinik Mitte, Germany; ${ }^{9}$ Klinikum Oldenburg gGmbH, Klinik für Innere Medizin, Germany; ${ }^{10}$ Universität Leipzig, Medizinische Klinik und Poliklinik II, Germany; ${ }^{11}$ Zentralkrankenhaus Bremen Ost, Germany; ${ }^{12}$ Klinikum der Stadt Ludwigshafen, Germany; ${ }^{13}$ Rheinische Friedrisch-Willhelms-Universität Bonn, I Medizinische Klinik, Germany; ${ }^{14}$ Ruhr-Universität Bochum, Medizinische Universitätsklinik, Knappschaftskrankenhaus, Germany; ${ }^{15}$ Universitätsklinikum Heidelberg, Medizinische Klinik IV, Germany; ${ }^{16}$ Städtisches Klinikum Esslingen, Germany; ${ }^{17}$ Universitätskliniken des Saarlandes, Innere Medizin II, Homburg, Germany.

\section{REFERENCES}

Assersohn L, Brown G, Cunningham D, Ward C, Oates J, Waters JS, Hill ME, Norman AR (2004) Phase II study of irinotecan and 5 -fluorouracil/leucovorin in patients with primary refractory or relapsed advanced oesophageal and gastric carcinoma. Ann Oncol 15: 64-69

Blanke CD, Haller DG, Benson AB, Rothenberg ML, Berlin J, Mori M, Hsieh YC, Miller LL (2001) A phase II study of irinotecan with 5-fluorouracil and leucovorin in patients with previously untreated gastric adenocarcinoma. Ann Oncol 12: 1575-1580

Blot WJ, Devesa SS, Kneller RW, Fraumeni JFJ (1991) Rising incidence of adenocarcinoma of the esophagus and gastric cardia. JAMA 265: $1287-1289$

Bouche O, Raoul JL, Bonnetain F, Giovannini M, Etienne PL, Lledo G, Arsene D, Paitel JF, Guerin-Meyer V, Mitry E, Buecher B, Kaminsky MC, Seitz JF, Rougier P, Bedenne L, Milan C (2004) Randomized multicenter phase II trial of a biweekly regimen of fluorouracil and leucovorin (LV5FU2), LV5FU2 plus cisplatin, or LV5FU2 plus irinotecan in patients with previously untreated metastatic gastric cancer: a Federation
Francophone de Cancerologie Digestive Group Study-FFCD 9803. J Clin Oncol 22: 4319-4328

Bouzid K, Khalfallah S, Tujakowski J, Piko B, Purkalne G, , Padrik P, Serafy M, Pshevloutsky EM, Boussard B (2003) A randomized phase II trial of irinotecan in combination with infusional or two different bolus 5fluorouracil and folinic acid regimens as first-line therapy for advanced colorectal cancer. Ann Oncol 14: 1106-1114

Bray F, Sankila R, Ferlay J, Parkin DM (2002) Estimates of cancer incidence and mortality in Europe in 1995. Eur J Cancer 38: 99- 166

Diaz-Rubio E (2004) New chemotherapeutic advanced in pancreatic, colorectal, and gastric cancers. The Oncologist 9: 282-294

Douillard JY, Cunningham D, Roth AD, Navarro M, James RD, Karasek P, Jandik P, Iveson T, Carmichael J, Alakl M, Gruia G, Awad L, Rougier P (2000) Irinotecan combined with fluorouracil compared with fluorouracil alone as first-line treatment for metastatic colorectal cancer: a multicentre randomised trial. Lancet 355: $1041-1047$

Futatsuki K, Wakui A, Nakao I, Sakata Y, Kambe M, Shimada Y, Yoshino M, Taguchi T, Ogawa N (1994) Late phase II study of irinotecan 
hydrochloride (CPT-11) in advanced gastric cancer. CPT-11 Gastrointestinal Cancer Study Group. Gan To Kagaku Ryoho 21: 1033-1038

Glimelius B, Ekstrom K, Hoffman K, Graf W, Sjoden PO, Haglund U, Svensson C, Enander LK, Linne T, Sellstrom H, Heuman R (1997) Randomized comparison between chemotherapy plus best supportive care with best supportive care in advanced gastric cancer. Ann Oncol 8: $163-168$

Hohenberger P, Gretschel S (2003) Gastric cancer. Lancet 362: 305-315

Kohne CH, Catane R, Klein B, Ducreux M, Thuss-Patience P, Niederle N, Gips M, Preusser P, Knuth A, Clemens M, Bugat R, Figer I, Shani A, Fages B, Di Betta D, Jacques C, Wilke HJ (2003) Irinotecan is active in chemonaive patients with metastatic gastric cancer: a phase II multicentric trial. Br J Cancer 89: 997-1001

Lee SH, Kang WK, Park J, Kim HY, Kim JS (2004) Combination chemotherapy with epirubicin, docetaxel and cisplatin (EDP) in metastatic or recurrent, unresectable gastric cancer. Br J Cancer 91: $18-22$

Mathijssen RH, van Alphen RJ, Verweij J, Loos WJ, Nooter K, Stoter G, Sparreboom A (2001) Clinical pharmacokinetics and metabolism of irinotecan (CPT-11). Clin Cancer Res 7: 2182-2194

Moehler M, Haas U, Siebler J, Schimanski C, Hertkorn C, Hoehler T, Galle PR, Heike M (2003) Weekly treatment with irinotecan, folinic acid and infusional 5-fluorouracil (ILF) in patients with advanced gastric cancer. Anticancer Drugs 14: 645-650

Murad AM, Santiago FF, Petroianu A, Rocha PR, Rodrigues MA, Rausch M (1993) Modified therapy with 5-fluorouracil, doxorubicin, and methotrexate in advanced gastric cancer. Cancer 72: 37-41

Park YH, Ryoo BY, Choi SJ, Kim HT (2004) A phase II study of capecitabine and docetaxel combination chemotherapy in patients with advanced gastric cancer. $\mathrm{Br} J$ Cancer 90: 1329-1333

Pozzo C, Barone C, Szanto J, Padi E, Peschel C, Bukki J, Gorbunova V, Valvere V, Zaluski J, Biakhov M, Zuber E, Jacques C, Bugat R (2004) Irinotecan in combination with 5-fluorouracil and folinic acid or with cisplatin in patients with advanced gastric or esophageal-gastric junction adenocarcinoma: results of a randomized phase II study. Ann Oncol 15: $1773-1781$

Pyrhonen S, Kuitunen T, Nyandoto P, Kouri M (1995) Randomised comparison of fluorouracil, epidoxorubicin and methotrexate (FEMTX) plus supportive care with supportive care alone in patients with nonresectable gastric cancer. $\mathrm{Br}$ J Cancer 71: 587-591

Rau B, Hunerbein M, Reingruber B, Hohenberger P, Schlag PM (1996) Laparoscopic lymph node assessment in pretherapeutic staging of gastric and esophageal cancer. Rec Res Cancer Res 142: 209-215

Rothenberg ML, Meropol NJ, Poplin E, Van Cutsem E, Walder S (2001) Mortality associated with irinotecan plus bolus fluorouracil/leucovorin: summary findings of an independent panel. J Clin Oncol 19: 3801-3807

Saltz LB, Cox JV, Blanke C, Rosen LS, Fehrenbacher L, Moore MJ, Maroun JA, Ackland SP, Locker PK, Pirotta N, Elfring GL, Miller LL (2000) Irinotecan plus fluorouracil and leucovorin for metastatic colorectal cancer. Irinotecan Study Group. N Engl J Med 343: $905-914$

Schoffski P (2002) New drugs for treatment of gastric cancer. Ann Oncol 13(suppl 4): 13-22

Schulze-Bergkamen H, Zuna I, Tuefel A, Stremmel W, Rudi J (2002) Treatment of advanced gastric cancer with etoposide, folinic acid and fluorouracil in the clinical setting: efficacy of therapy and value of serum tumour markers. Med Oncol 19: 43-53

Therasse P, Arbuck SG, Eisenhauer EA, Wanders J, Kaplan RS, Rubinstein L, Verweij J, Van Glabbeke M, van Oosterom AT, Christian MC, Gwyther SG (2000) New guidelines to evaluate the response to treatment in solid tumors. European Organization for Research and Treatment of Cancer, National Cancer Institute of the United States, National Cancer Institute of Canada. J Natl Cancer Inst 92: 205-216

Vanhoefer U, Rougier P, Wilke H, Ducreux MP, Lacave AJ, Van Cutsem E, Planker M, Santos JG, Piedbois P, Paillot B, Bodenstein H, Schmoll HJ, Bleiberg H, Nordlinger B, Couvreur ML, Baron B, Wils JA (2000) Final results of a randomized phase III trial of sequential high-dose methotrexate, fluorouracil, and doxorubicin versus etoposide, leucovorin, and fluorouracil versus infusional fluorouracil and cisplatin in advanced gastric cancer: A trial of the European Organization for Research and Treatment of Cancer Gastrointestinal Tract Cancer Cooperative Group. J Clin Oncol 18: 2648-2657

Waters JS, Norman A, Cunningham D, Scarffe JH, Webb A, Harper P, Joffe JK, Mackean M, Mansi J, Leahy M, Hill A, Oates J, Rao S, Nicolson M, Hickish T (1999) Long-term survival after epirubicin, cisplatin and fluorouracil for gastric cancer: results of a randomized trial. $\mathrm{Br} \mathrm{J}$ Cancer 80: $269-272$ 